\title{
COARCTATION OF AORTA AND TAKAYASU ARTERITIS FOR LSCS:
} ANAESTHESIA MANAGEMENT

\author{
Rashmi Bengali ${ }^{1}$, Tushar Patil ${ }^{2}$
}

\section{HOW TO CITE THIS ARTICLE:}

Rashmi Bengali, Tushar Patil. "Coarctation of Aorta and Takayasu Arteritis for LSCS: Anaesthesia Management". Journal of Evolution of Medical and Dental Sciences 2015; Vol. 4, Issue 82, October 12; Page: 14427-14431, DOI: $10.14260 /$ jemds/2015/2052

\begin{abstract}
Coarctation of aorta is a congenital disorder with 5-10\% incidence. It occurs in about 1 in 10,000 births .It may remain asymptomatic till adulthood. During pregnancy, early gestational hypertension is the presenting sign. Difference in blood pressure in upper and lower limb is a characteristic finding of coarctation of aorta. Association of bicuspid aortic valve and ventricular septal defect is seen in $50 \%$ patients of coarctation. Major cardiovascular complications are infrequent but continue to be a source of concern for patients with coarctation who become pregnant. Coarctation of aorta commonly located at the junction of the arch of aorta and proximal descending aorta at the level of ductal structure, may be diagnosed for the first time during pregnancy. Dilatation and dissection of the aorta can lead to increased maternal mortality; significant stenosis is a contraindication to pregnancy. However, successful pregnancies have been reported in women with uncorrected coarctation if preconception risk stratification is done. Here is a case of LSCS with coarctation of aorta and Takayasu arteritis done successfully under epidural anaesthesia.
\end{abstract}

KEYWORDS: Coartation of aorta, Takayasu Arteritis, LSCS, Hypertension, Regional Anaesthesia.

INTRODUCTION: Among the common congenital heart diseases the share of coarctation of aorta is 5 to $10 \%$ with male to female ratio $2: 1 .^{1}$ Pregnancy with coarctation of aorta for cesarean section is a special situation to be managed by anaesthetist. Such patients are prone for cardiovascular decompensation and complication can occur in the form of left ventricular failure, aortic rupture, cerebro-vascular accidents or infective endocarditis. Maternal mortality is almost 3-8\%. However site and severity of coarctation, presence of aneurysm, associated cardiac signs decide the risk of individual. Neonatal complications like growth retardation, placental abruption and premature delivery are also known to occur.

Here we are presenting a case of Coarctation of aorta with Takayasu arteritis posted for LSCS done successfully under epidural anaesthesia.

CASE REPORT: A 23 years, second gravida was admitted to the hospital for emergency cesarean section. She was diagnosed to have Coarctation of aorta at 6 months of gestation during her first pregnancy and was advised Tab. Atenolol 25mg, Tab. Nicardia 10mg, Tab. Hydrochlorthiazide 12.5mg and Tab. Prazocin 5mg once a day. She underwent cesarean section uneventfully with history of 3 units of blood transfusions. She was referred to Cardiac center for further surgical correction but instead she continued the same treatment since last 6 years. This time she reported at 37 weeks with same treatment except Tab Prazocin. During the course of pregnancy she had breathlessness and palpitations off and on. Her radial pulse rate was $64 / \mathrm{min}$ regular on right side while $51 / \mathrm{min}$ on left side. The femoral pulsations on left side were feeble. BP on right arm was $176 / 96 \mathrm{~mm}$ of $\mathrm{Hg}$ while 104/58mm of Hg. on left arm. 
BP on left leg was $90 / 60 \mathrm{~mm}$ of $\mathrm{Hg} . \mathrm{SpO}_{2}$ was showing $99 \%$ saturation in all four limbs. This shows that collaterals were well developed. There was radio femoral delay. A soft bruit was heard on scapular region. Her Haemogram, LFT, KFT, Serum Electrolytes were unremarkable. ECG was suggestive of left ventricular hypertrophy with strain pattern. 2D Echo revealed severe concentric LVH with mild hypokinesia of left ventricle. There was thickening of aortic and mitral valve with mild regurgitation. Ejection fraction was $60 \%$. CT Thorax revealed circumferential narrowing involving post ductal part of descending aorta suggestive of coarctation of aorta.

Similar changes were seen in subclavian and left common carotid artery suggestive of Takayasu Arteritis with fibro-muscular dysplasia. She was posted for elective LSCS. Patient was informed about the disease progress and outcome of baby and accordingly informed consent was taken. Multipara monitor with heart rate, NIBP, ECG, $\mathrm{SpO}_{2}$ was applied. Antiemesis prophylaxis was given with IV 4mg Ondensetron and IV 50mg Ranitidine. Antibiotic coverage was given with IV $1 \mathrm{mg}$ Cefotaxim and IV 80mg Gentamycin. Under all aseptic precautions 18G epidural catheter was inserted in L3-L4space in lateral position. Test dose of 2cc of $2 \%$ lignocaine was injected.

Patient was made supine and wedge was put below right buttock. Oxygen supplementation was started with $4 \mathrm{~L}$ by mask. Further incremental doses of $0.5 \%$ Bupivacaine were given (Total 11cc) and desired level was achieved up-to T6. Patient was haemodynamically stable throughout. Good saturation in lower limbs suggested well maintained fetal and vital organ perfusion. $2 \mathrm{~kg}$ baby was delivered with Apgar score 9/10. Intraoperative course was uneventful. Postoperative analgesia was achieved by Inj. Tramadol $1.5 \mathrm{mg} / \mathrm{Kg}$ given epidurally. Her antihypertensive regime was restarted. Patient was discharged on $12^{\text {th }}$ postoperative day.

DISCUSSION: Coarctation of aorta is a defect of constricted aortic segment with localized medial layer thickening causing posterior in folding or posterior shelf. The aneurysm formation is a result of elastic tissue proliferation in the intemal layer distal to coarctation. ${ }^{2}$ The common coarctations are juxtaductal. The coarcted segment may have irregular lumen considered as inflammatory or autoimmune and may be variant of Takayasu Arteritis. The defect is generally associated with bicuspid aortic valve carrying increased risk of infective endocarditis or ventricular septal defect seen in almost $50 \%$ of patients; whereas $3-5 \%$ patients may have intracranial aneurysms. Incidence of Patent ductus arteriosus is common in children.

Few patients may show extracardiac nonvascular anomalies of respiratory, genitourinary or skeletal system etc. It is also a common cardiac defect seen in Turner syndrome. Suspicion of coarctation arises with occurance of congestive heart failure in childhood while adults generally present with hypertension, leg cramps and claudication or muscle weakness. In our patient there was circumferential narrowing involving post ductal part of descending aorta and similar changes were seen in subclavian and left common carotid artery suggestive of Takayasu Arteritis with fibromuscular dysplasia. Her ejection fraction was 60\%.No other associated anomaly was found.

Takayasu arterities (TA)was first described in 1908 by two Japanese ophthalmologists Takayasu and Onishiwho. ${ }^{3}$ Takayasu Arteritis (TA) is a chronic, inflammatory, progressive, idiopathic disease that causes narrowing, occlusion, and aneurysms of systemic and pulmonary arteries affecting especially the aorta and its branches. It has peak incidence in second decade with female preponderance. Though idiopathic, the cause may be related to auto-immunity, sex harmone or genetics (Demonstrated by the predisposition of the human leukocyte antigen-HLA BW52).4 
Four types of Takayasu Arteritis can be identified: Type I-disease involving the aortic arch and its branches, type II-lesions restricted to descending thoracic aorta and abdominal aorta, type IIIpatients have characteristics of types I and II, and type IV -involvement of the pulmonary artery. ${ }^{5}$ Our patient had type 1 disease. The disease can also be classified into stages according to the presence of major complications such as hypertension, retinopathy, aneurysms, and aortic insufficiency. ${ }^{6}$ Stage Ino complications are observed; Stage IIa,-patients have only one of these complications; and Stage IIb,-patients have only one of these complications, but the severe form; Stage III,-when more than one complication is present. Our patient was Stage IIa.

Due to ductus constriction, Coarctation of the aorta imposes significant afterload on the left ventricle (LV), resulting into increased wall stress, increase left ventricular pressure and compensatory ventricular hypertrophy. This can increase left atrial pressure opening the foramena ovale and resultant dilatation of right atrium and ventricle. When foramena ovale does not open, the rise in pulmonary pressure can also cause dilatation of right ventricle. Cardiomegaly revealed by chest X-ray and right ventricular hypertrophy seen on ECG and echocardiography are related to the indirect effects of rapid development of severe aortic obstruction which was evident in our patient. As LV afterload increases gradually, arterial collateral vessels develop that partially bypass the aortic obstruction. These patients may be asymptomatic until hypertension is detected or any other complication develops. ${ }^{7}$ the collaterals were well developed in our patient, evident by good utreroplacental flow and good oxygen saturation of lower limbs.

Clinical diagnosis of coarctation of aorta is based on the difference in blood pressure and pulse of upper and lower limbs. Feeble or delayed pulse distal to obstruction and difference in blood pressure of $35 \mathrm{mmHg}$ between the right arm and lower limb in adults is characteristic peculiarity of coarctation. Ideally all gestational hypertensive patients should be examined for radio -femoral delay and differential blood pressures so as to aid in the early diagnosis of coarctation. Along with cardiomegaly, X-ray chest shows rib notching and prominent aortic knuckle with thoracic indentation, while narrowing of isthumus is seen on Echocardiography. MRI is of prime importance to denote location and extent of coarctation and the collaterals. Detection and monitoring of aneurysm can also be done on MRI.

Pregnancy with coarctation and Takayasu arteritis presents with early gestational hypertension. The physiological increase in blood volume and oestrogen levels also contribute to hypertension and resultant dilatation or dissection of aorta. The aorta possesses histologically evident cystic medial necrosis making it vulnerable to dissection. The risk of complications like dissection or congestive cardiac failure increases in late pregnancy or within 6 weeks postpartum due to haemodynamic changes. Intrauterine growth retardation, abruption placenta or premature delivery mandate proper control and monitoring of hypertension in order to maintain uteroplacental perfusion. ${ }^{8}$ Along with alpha methyl dopa, Labetolol an alpha-Beta blocker is preferred for control of hypertension while digoxine and diuretics play role in congestive cardiac failure. ACE inhibitors and Ca channel blockers are contraindicated being teratogenic and can cause precipitous fall in BP respectively. Though surgical correction is preferred prior to pregnancy, severe uncontrolled hypertension leading to uterine hypoperfusion, haemodynamically significant aortic stenosis or heart failure demand correction during pregnant course.

A multidisciplinary approach is required in the management of such case. Anaesthetic goal in patients with coarctation and Takayasu Arteritis is maintenance of BP during perioperative period. Uncontrolled hypertension in Takayasu arteritis can result into end organ dysfunction and stenosis of 
major blood vessels affecting regional circulation. Though elective LSCS is recommended, recent European Society of Cardiology (ESC) guidelines suggest vaginal delivery under epidural anesthesia as a safer mode. ${ }^{9}$ Epidural anaesthesia does not cause sudden drop in blood pressure maintaining the better haemodynamics. The increase in cardiac output due to pregnancy and uterine contractions may result into cardiac decompensation which is better avoided under epidural anaesthesia. Any sudden drop in blood pressure will affect the lower limb perfusion compromising uteroplacental flow. In addition, patient's level of consciousness is a marker for brain perfusion. Under general anaesthesia chances of aortic rupture or dissection are increased during intubation and extubation due to rise in BP, whereas inadequate depth of anaesthesia can result into cerebral haemorrhage and rupture of aneurysm. ${ }^{6,10}$ Arterial line was not put in our case as repeated cannulation can injure the arteries which can pose problem during coarctoplasty.

Though antenatal period is managed conservatively, significant coarcatation or recoarctation with long standing hypertension or patient with haemodynamically significant aortic stenosis and female patient contemplating pregnancy indicate surgical intervention like balloon dilatation with or without stenting, Dacron patch aortoplasty or surgical correction with dissection of paracoarctation tissue.

CONCLUSION: Coarctation of the aorta is a lifelong disease with a guarded prognosis. Relief of obstruction, control of hypertension, follow-up monitoring for recurrent obstruction, and follow-up care of associated anomalies are imperative

Multidisciplinary approach of physician, cardiologist and anesthetist is important during the management of LSCS to have better outcome. The uneventful course of anaesthesia in the present case was related to the thorough systemic evaluation and careful anaesthetic strategy.

\section{REFERENCES:}

1. Yavuz C, Soydinc HE, Tekbaş G and Karahan O. Pregnancy Complicated with Severe Recurrent Aortic Coarctation: Case Rep Vasc Med 2012; Article ID 865035.

2. Wald RM, Sermer M, and Colman JM. Pregnancy in young women with congenital heart disease: Lesion-specific considerations. Paediatr Child Health. 2011; 16: e33-e37.

3. Matsumura A, Moriwaki R, Numano F - Pregnancy in Takayasu arteritis from the view of internal medicine. Heart Vessels; 7(Suppl): 120-124, (1992).

4. Wilke WS - Large vessel vasculitis (giant cell arteritis, Takayasu arteritis). BaillieresClinRheumatol, 1997; 11: 285-313.

5. Lupi-Herrera E, Sanchez-Torres G, Marcushamer J et al. - Takayasu's arteritis. Clinical study of 107 cases. Am Heart J, 1977; 93: 94-103.

6. Ishikawa K - Natural history and classification of occlusive thromboaortopathy (Takayasu's disease). Circulation, 1978; 57: 27-35.

7. Rudolph AM, Heymann MA, Spitznas U. Hemodynamic considerations in the development of narrowing of the aorta. Am J Cardiol. 1972 Oct. 30(5): 514-25.

8. Connolly HM. Pregnancy in women with coarctation of the thoracic aorta. ACC Curr J Rev 1997; 55: 6-7.

9. Warnes CA, Williams RG, Bashore TM, Child JS, Connolly HM, Dearani JA, et al. ESC Guidelines on the management of cardiovascular diseases during pregnancy: 2011; 32: 3147-3197. 


\section{CASE REPORT}

10. Henderson K, Fludder P - Epidural anaesthesia for caesarean section in a patient with severe Takayasu's disease. Br J Anaesth; 83: 956-959, (1999).

\section{AUTHORS:}

1. Rashmi Bengali

2. Tushar Patil

\section{PARTICULARS OF CONTRIBUTORS:}

1. Associate Professor, Department of Anaesthesia. Govt. Medical College Aurangabad.

2. Professor \& HOD, Department of Anaesthesia. Govt. Medical College Aurangabad.

FINANCIAL OR OTHER COMPETING INTERESTS: None

\section{NAME ADDRESS EMAIL ID OF THE} CORRESPONDING AUTHOR:

Dr. Rashmi Bengali.

C-19, Town Centre, Cidco, Aurangabad.

E-mail: drrvbengali@gmail.com

Date of Submission: 21/09/2015. Date of Peer Review: 22/09/2015. Date of Acceptance: 03/10/2015. Date of Publishing: 12/10/2015. 